\title{
Differences in Pelvic Fin Length Represent Sexual Dimorphism in Utah Chub (Gila atraria)
}

\author{
Mark C. Belk ${ }^{1, *}$, Scott Bird ${ }^{1}$, Mehmet Cemal Oguz ${ }^{2}$ and Jerald B. Johnson ${ }^{1,3}$
}

${ }^{I}$ Department of Biology Brigham Young University, Provo, Utah 84602, USA; ${ }^{2}$ Biology Department, Faculty of Science, Ataturk University, 25240, Erzurum, Turkey; and Visiting Professor, Department of Biology, Brigham Young University, Provo UT, 84602, USA; ${ }^{3}$ Monte L. Bean Life Science Museum, Brigham Young University, Provo, UT, 84602

\begin{abstract}
The cyprinid fish Gila atraria Girard (Utah chub) is generally considered a sexually monomorphic species. However, prior observations revealed variation in pelvic fin length within populations that appears sexually dimorphic. We measured the relative pelvic fin length of 419 sexually mature Utah chub from 8 different locations to determine the magnitude and generality of this apparent dimorphism. Pelvic fin length in G. atraria differs between sexes by about $10 \%$ on average; males have longer pelvic fins than females. The dimorphism is general across all locations, but it is not related to body size. Magnitude of the dimorphism varies by predation environment - the difference between males and females is slightly greater in low predation environments. We find no evidence for an adaptive function for this dimorphism; however, it does provide an efficient mechanism for determining sex without dissection.
\end{abstract}

Keywords: Cyprinidae, Gila atraria, pelvic fin length, sexual dimorphism, Utah chub.

\section{INTRODUCTION}

Utah chub (Gila atraria) is a member of the family Cyprinidae, and is generally considered a sexually monomorphic species [1], other than some temporary dichromatism during the breeding season in which males display a slight gold coloration [2] relative to females. However, in a large sample of Utah chub collected in connection with other work [1], we observed an apparent sexual dimorphism in pelvic fin length. Males appeared to have longer pelvic fins than females. Dimorphism in pelvic fin length has not been reported for any species in the genus Gila. Hence, this represents a novel trait with an unknown function.

At least two factors could contribute to sexual dimorphism in fin length in Utah chub. It could be that differences are due to sexual selection. However, there are no known sexual displays in this species and direct male-male competition has not been documented. What we do know is that populations of Utah chub vary dramatically in life history and growth rates in response to predation environment [1] and that considerable genetic variation associated with geographic locations exists among populations of Utah chub [3]. If sexual dimorphism in pelvic fin length is due to sexual selection, it is possible that predation environment could affect the degree of dimorphism. Several empirical studies have shown that dimorphic traits are less exaggerated in environments with higher predation risk [4-6]. Hence, we predict that in the presence of predators we could see less sexual dimorphism than in predator free environments. A nonadaptive explanation could also account for differences in fin

*Address correspondence to this author at the Department of Biology Brigham Young University, Provo, Utah 84602, USA;

Tel: (801) 422-4154; Fax: (801) 422-0090;

E-mail: mark_belk@byu.edu length between males and females. Adult body size varies considerably among populations [1] and it is possible that allometric differences in fin growth rate as a function of body size could account for differences in dimorphism among populations. If so, we expect to see the degree of sexual dimorphism among populations change as a function of adult body sizes.

To determine the magnitude and generality of this apparent sexual dimorphism, we measured relative pelvic fin length of male and female Utah chub from eight locations. These locations represent the breadth of environmental variation, genetic variation, and natural geographic distribution of Utah chub with four populations occurring with cutthroat trout predators and four found in the absence of predators [1, $3,7]$. In this study we address three questions. First, we ask if sexual dimorphism in fin length is found among populations throughout the range of this species. Second, we ask if populations that occur with predators show a lower degree of dimorphism than those found without predators. Finally, we ask if the degree of sexual dimorphism changes as a function of overall body size, suggesting an allometric effect.

\section{METHODS}

We measured the fin length of individuals from eight locations in the Bonneville Basin and upper Snake River drainage. The collection locations are as follows: 1) Fish Springs, Utah ( $\left.39^{\circ} 53^{\prime} 13.58^{\prime \prime N}, 113^{\circ} 24^{\prime} 48.51^{\prime \prime W}\right)$, 2) Rush Lake, Utah ( $\left.\left.40^{\circ} 26^{\prime} 27.43^{\prime \prime} \mathrm{N}, 112^{\circ} 23^{\prime} 02.85^{\prime \prime W}\right), 3\right)$ Big Spring, Utah $\left(40^{\circ} 44^{\prime} 26.23^{\prime \prime N}, 112^{\circ} 38^{\prime} 49.65^{\prime \prime}\right)$, 4) Locomotive Springs, Utah (41 $\left.42^{\circ} 36.78^{\prime \prime} \mathrm{N}, 112^{\circ} 55^{\prime} 24.20^{\prime \prime} \mathrm{W}\right)$, 5) Bear Lake, Utah and Idaho (41 $\left.{ }^{\circ} 58^{\prime} 49.63^{\prime \prime N}, 111^{\circ} 23^{\prime} 47.37^{\prime \prime} \mathrm{W}\right)$, 6) Jackson Lake, Wyoming $\left(43^{\circ} 53^{\prime} 41.244^{\prime \prime} \mathrm{N}, 110^{\circ} 40^{\prime}\right.$

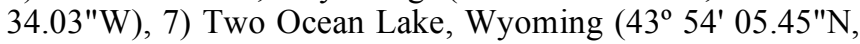
$\left.110^{\circ} 30^{\prime} 24.64 " \mathrm{~W}\right)$, and 8) Heart Lake, Wyoming (44 $17^{\circ}$ 
$\left(44^{\circ} 17^{\prime} 04.34^{\prime \prime} \mathrm{N}, 110^{\circ} 29^{\prime} 35.46^{\prime \prime} \mathrm{W}\right)$ [1]. In locations 5-8, Utah chub coexist with a natural predator, cutthroat trout, Oncorhynchus clarki Richardson, in large lakes. The other four locations (1-4) are small spring-associated ponds or spring complexes where $O$. clarki does not occur. For a map of these locations, see Johnson and Belk [1]. Fish were collected using experimental gill nets as described in Johnson and Belk [1]. Sex was determined by direct observation of gonads, and standard length (SL) was measured to the nearest $\mathrm{mm}$. Pelvic fins were measured when laid flat against the body from the anterior origin to the tip. Left and right fins were measured separately, and the mean of the two fin lengths was used in the analysis. Only adults were used in this study $(\mathrm{n}=419)$, and fish with damaged or missing fins were not included.

To test for sexual dimorphism in fin length and variation in the sexual dimorphism associated with predator or nonpredator environments we used a mixed model design of analysis of covariance (ANCOVA) [8]. The response variable was pelvic fin length (natural log transformed). We used a natural $\log$ transform of fin length to better meet the assumptions of normally distributed residuals. Main fixed effects in the model were predation environment (two levels) and sex (two levels), and we included the interaction term. We included the covariate standard length (SL; also natural $\log$ transformed) to account for effects of variation in size among individuals. Collection location was included as a random effect. In this model a significant sex effect would confirm the generality of the sexual dimorphism in fin length, a significant effect of predation environment would indicate that fin length varied between predator and nonpredator environments independent of the sex effect, and a significant interaction would indicate the sexual dimorphism in fin length varied systematically between predation environments. To test for generality of the dimorphism among locations we ran a second ANCOVA. Pelvic fin length was the response variable, sex and location were main effects, SL was a covariate, and the interaction of the main effects was also included.

To test for isometry in the pelvic fin length to SL relationship we used reduced major axis regression (RMA) [9] on data combined across all locations. Although the above ANCOVA models provide an estimate of the linear regression slope of the relationship between pelvic fin length and $\mathrm{SL}$, the RMA regression accounts for measurement with error in both variables and thus provides a better estimate of the slope [10]. We tested sexes separately. A slope equal to one indicates isometry in the relationship.

\section{RESULTS}

Male G. atraria have longer pelvic fins than females. Fin length differed significantly between sexes, after adjusting for the covariate standard length, and there was a significant interaction between sex and predation environment. Predation environment alone was not a significant predictor of pelvic fin length (Table 1). Mean male pelvic fin length (least squares means) was $19.14 \mathrm{~mm}$, and mean female pelvic fin length was $17.14 \mathrm{~mm}$ after adjusting for variation in SL. This represents a $10.5 \%$ difference between sexes in pelvic fin length across all body sizes. The significant interaction between sex and predation environment indicates that differences in pelvic fin length between males and females were slightly greater in non-predator environments than in predator environments (Fig. 1). However, pelvic fin length is significantly different between sexes in both environments (post-hoc means test; non-predator environment: difference $=0.135, \mathrm{df}=409, \mathrm{t}$-value $=12.33$, $\mathrm{P}$-value $<0.0001$; predator environment: difference $=0.086$, $\mathrm{df}=410$, t-value $=5.35$, P-value $<0.0001)$. Pelvic fin length varied among locations, and the magnitude of sexual dimorphism varied among locations (Table 2). Males consistently displayed longer pelvic fins than females in all collection locations (Fig. 2). Pelvic fin length increased nearly isometrically with standard length in both males and females (male slope $1.02,95 \%$ confidence interval $0.97-1.07$; female slope $1.06,95 \%$ confidence interval $1.03-1.1$ ), with slope just slightly greater than 1.0 in females. On live G. atraria the relative difference in pelvic fin length between sexes is readily apparent (Fig. $\mathbf{3}$ ).

Table 1. Analysis of variance results for the test of pelvic fin length by sex and predator environment. Collection locations were used as a random effect. Logtransformed standard length (LSL) was used as a covariate.

\begin{tabular}{|c|c|c|c|}
\hline Effect & $\begin{array}{c}\text { Degrees of } \\
\text { Freedom }\end{array}$ & F Value & Pr $>$ F \\
\hline \hline SEX & 1,411 & 129.01 & $<.0001$ \\
\hline Pred & $1,7.78$ & 0.41 & 0.5427 \\
\hline LSL & 1,413 & 1865.45 & $<.0001$ \\
\hline SEX * Pred & 1,410 & 6.48 & 0.0113 \\
\hline
\end{tabular}

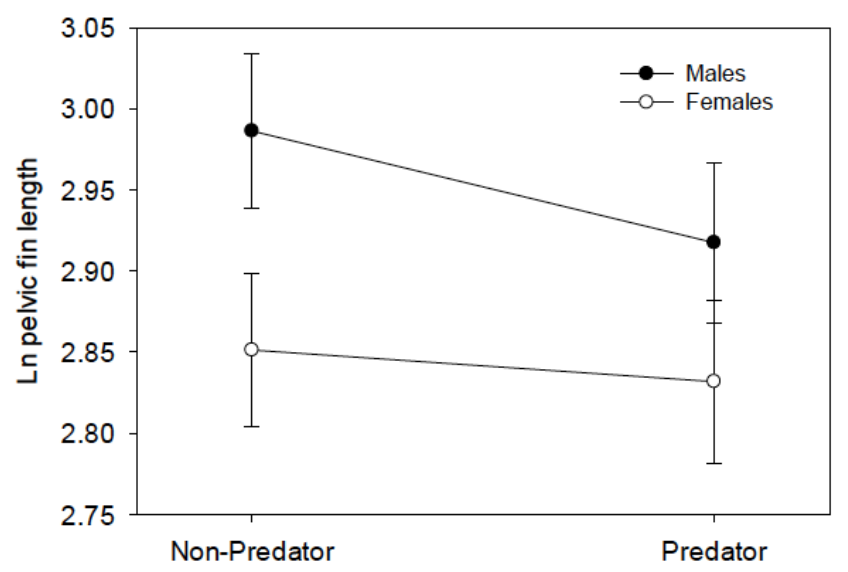

Fig. (1). Least-squares means ( \pm SE) of pelvic fin length (logtransformed) by predation environment and sex.

\section{DISCUSSION}

Pelvic fin length is sexually dimorphic in Utah chub within all locations we sampled and within both predator environments. We suggest that this sexual dimorphism is a consistent characteristic of the species. All of the locations we sampled exhibited the same pattern of dimorphism even though the absolute magnitude of the dimorphism was somewhat variable (Fig. 2). 
Table 2. Analysis of variance results for the test of pelvic fin length by sex and collection location. Logtransformed standard length (LSL) was used as a covariate.

\begin{tabular}{|c|c|c|c|}
\hline Effect & $\begin{array}{c}\text { Degrees of } \\
\text { Freedom }\end{array}$ & F Value & $\operatorname{Pr}>\mathbf{F}$ \\
\hline \hline LOC & 7,402 & 61.33 & $<.0001$ \\
\hline SEX & 1,402 & 120.85 & $<.0001$ \\
\hline LSL & 1,402 & 1824.47 & $<.0001$ \\
\hline LOC*SEX & 7,402 & 2.15 & 0.0376 \\
\hline
\end{tabular}

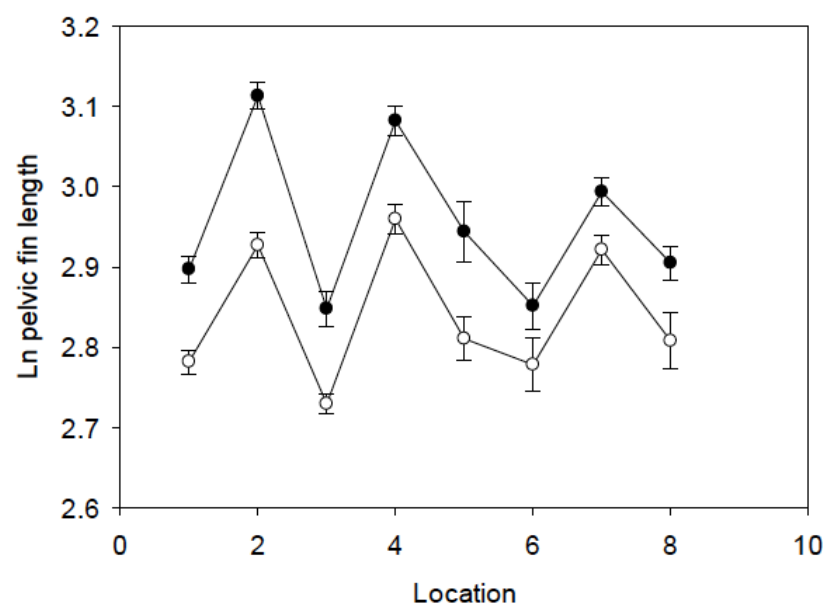

Fig. (2). Least-squares means ( \pm SE) of pelvic fin length (logtransformed) by location and sex.
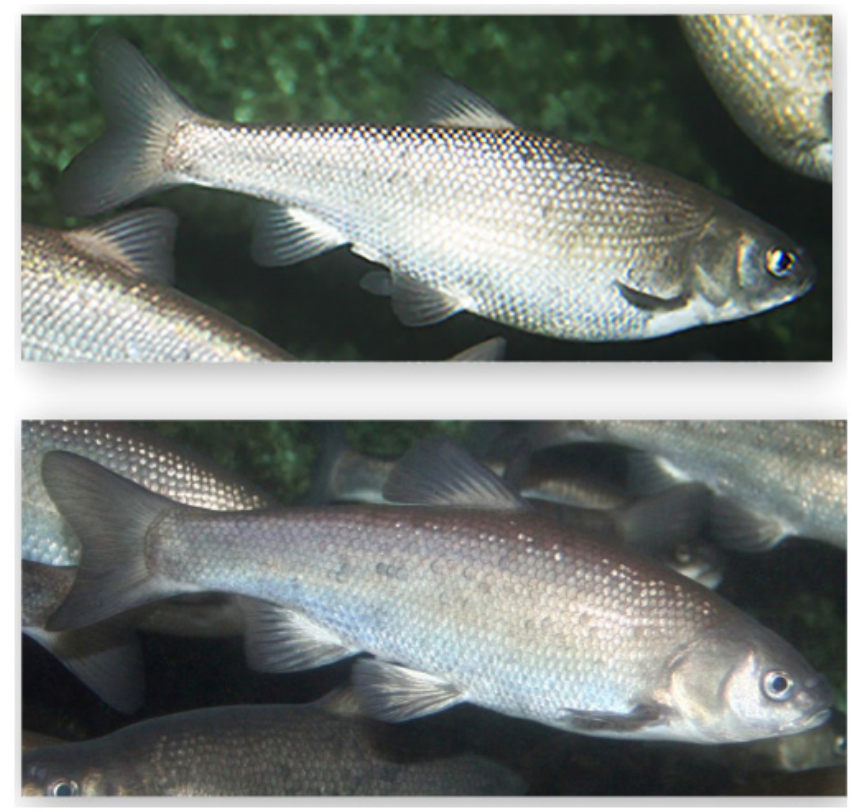

Fig. (3). Photos of female (top) and male (bottom) G. atraria illustrating relative difference in pelvic fin length between sexes. Note the difference between the terminus of the pelvic fin and the position of the anal fin. In males the pelvic fins reach nearly to the anal fin. In females the pelvic fins end well short of the anal fin.
Sexual dimorphism in fin length is slightly greater in locations without predators (locations 1-4) compared to locations with predators (locations 5-8). Many Utah chub traits are known to vary between predator and non-predator locations. For example, Utah chub that share habitat with $O$. clarki show increased juvenile growth rates, delayed sexual maturity, and increased size at maturity [1]. The variation in sexual dimorphism between predator and nonpredator environments is slight, and it is not clear if predation environments influence this dimorphism directly. Although this study does not test sexual selection as a means whereby this dimorphism arises, it is possible that sexual selection is the cause of the dimorphism and that the presence of a predator acts in opposition to this form of selection. For example, in the Trinidad guppy, Poecilia reticulata, females selectively choose brightly colored males in a predator free environment. In a predator environment, however, they tend to favor less colorful $[4,5]$. If sexual dimorphism of pelvic fin length in Utah chub is caused by sexual selection, it may also be less extreme in high predation environments.

Body size variation does not influence the presence or degree of fin length dimorphism in Utah chub. Regression slope for males did not differ from one, indicating that relative fin length does not change with increasing body size. Regression slope for females was just slightly greater than one, such that the difference in fin length between sexes becomes slightly less pronounced with increasing body size. Although juveniles were not included in the study, the presence of the dimorphism among all adult body sizes could indicate that juveniles also exhibit this dimorphism. Alternatively, this difference might begin to develop during the juvenile stage and become fully developed when the fish reach sexual maturity. In either case, all adults appear to exhibit the dimorphism despite variation in size and age.

The function, if any, of dimorphic pelvic fin length in Utah chub is unclear. Other cases of dimorphic pelvic fin length exist in the family Cyprinidae [11-13]. In one species, Barilius barna Hamilton, dimorphic pelvic fin length is connected with male behaviors of digging burrows and holding onto rocks during the breeding season. In that species, the pelvic fin of males is modified to be large and muscular at the base [13]. In another species, pelvic fin dimorphism seems to be associated with mating displays [12]. In Utah chub, fin length dimorphism isn't marked by musculature or thickness differences, so it seems unlikely that this trait plays a role in functional male reproductive behaviors. Utah chub are group spawners [14]. A female is followed by several males and eventually deposits eggs in various substrates in about one-half meter of water. The eggs hatch about a week later and there is no report of parental care of eggs or offspring [2]. There is no suggestion from this breeding behavior that dimorphism may serve some sort of display function. Hence, sexual dimorphism in fin length may represent a nonadaptive trait or by-product of some other aspect of sexual differentiation on Utah chub.

This dimorphism provides a straightforward and reliable mechanism for determining sex in live individuals or in field collections without the need for dissection. Researchers can use this dimorphism to determine sex ratios and differences in body size between sexes. Although Utah chub is not of conservation concern as a species, there are several isolated 
populations that are genetically and ecologically unique [7]. Research on and management of these populations will be facilitated by an understanding of this pelvic fin dimorphism.

\section{CONFLICT OF INTEREST}

The authors confirm that this article content has no conflict of interest.

\section{ACKNOWLEDGEMENTS}

We thank the M.L. Bean Life Science Museum for access to the samples of Utah chub. We thank the Biology Department at BYU for continued support of mentored research opportunities for undergraduates.

\section{REFERENCES}

[1] Johnson JB, Belk MC. Effects of predation on life-history evolution in Utah chub (Gila atraria). Copeia 1999; 4 : 948-57.

[2] Sigler WF, Sigler JW. Fishes of the Great Basin: A natural history. university of nevada press: Reno, Nevada 1987.

[3] Johnson JB. Evolution after the flood: phylogeography of the desert fish Utah chub. Evolution 2002; 56: 948-60.

[4] Stoner G, Breden F. Phenotypic differentiation in female preference related to geographic variation in male predation risk in the
Trinidad guppy (Poecilia reticulata). Behav Ecol and Sociobiol 1988; 22: 285-91.

[5] Endler JA. Natural selection on color patterns in Poecilia reticulata. Evolution 1980; 34: 76-91.

[6] Forsgren E. Predation risk affects mate choice in a Gobiid fish. Am Nat 1992; 140: 1041-9.

[7] Johnson JB, Belk MC. What the status of Utah chub tells us about conserving common, widespread species. Am Fish Soc Symp 2007; 53: 165-74.

[8] Littell RC, Milliken GA, Stroup WW, Wolfinger RD. SAS system for mixed models. Cary: SAS Institute Inc 1996.

[9] Bohonak AJ. RMA: Software for reduced major axis regression. San Diego, California: San Diego State University 2004. Available from: http://www.bio.sdsu.edu/pub/andy/RMA.html.

[10] Sokal RR, Rohlf FJ. Biometry: the principles and practices of statistics in biological research, $2^{\text {nd }}$ edition. Freeman: San Francisco 1981

[11] Gante HF, Santos CD, Alves MJ. A new species of Chondostrima Agassiz, 1832 (Cypriniformes: Cyprinidae) with sexual dimorphism from the lower Rio Tejo Basin, Portugal. Zootaxa 2007; 1616: 23-35.

[12] Vainikka A, Kortet R, Paukku S, Rantala MJ, Pirhonen J. What do male tench, Tinca tinca, advertise with morphological ornaments? Acta Ethologica 2005; 8: 70-8.

[13] Raagam PM, Devi KR. An overview of the hill trouts (Barilius spp.) of the Indian region. Zoos' Print J 2005; 20: 1847-9.

[14] Pyron M. Mass and reproductive mode of minnows. Behav Ecol and Sociobiol 2000; 48:132-6.

(C) Belk et al.; Licensee Bentham Open.

This is an open access article licensed under the terms of the Creative Commons Attribution Non-Commercial License (http://creativecommons.org/licenses/by-nc/3.0/) which permits unrestricted, non-commercial use, distribution and reproduction in any medium, provided the work is properly cited. 